\title{
Design and implementation challenges of energy saving projects in underdeveloped countries and their perspective solutions in the light of project management principles - a review
}

\begin{abstract}
Infrastructure development in project management process tend to consume more energy and waste more natural resources where higher emission of carbon dioxide and pollution of the surrounding environment other than. Infrastructure consumed a large amount of large amount of energy and materials, which is comparable to cities in countries like Malaysia. This paper reviewed that the role of construction industry specifically for green building development is significant. Though the field of project management is grabbing importance yet certain related issues like land availability and ignorance of people along with certain technical insufficiencies are to be investigated in countries like Malaysia. Energy saving techniques or methods like cogeneration and trigeneration is highlighted and discussed as it is discovered as a key which worked as a backup source of energy supply to avoid interruption.
\end{abstract}

Keyword: Project management; Infrastructure; Energy; Efficiency; Emission; Cogeneration; Trigeneration; Insufficiency etc. 